\title{
Belt Road Initiatives (BRI): Intensi Supremasi Tiongkok di Samudra Hindia dan Respon Counterbalance dari India
}

\author{
Danika Ramadhani Azizah Fabtian \\ Departemen Hubungan Internasional \\ Universitas Airlangga
}

\begin{abstract}
ABSTRAK
Samudra Hindia dan wilayah sekitarnya merupakan lokasi strategis yang menarik banyak negara, termasuk India dan Tiongkok. Kedua negara ini memiliki persaingan yang didasari atas keinginan untuk menjadi hegemon demi menyebarkan pengaruh budaya, politik, ekonomi, hingga militer di wilayah perairan ini. Persaingan ini semakin menguat semenjak Tiongkok menginisiasikan Belt and Road Initiatives (BRI) yang dipandang India sebagai strategi komprehensif untuk semakin melegitimasi presensi hegemon Tiongkok di wilayah yang diklaim India sebagai tanggung jawabnya. India menanggapi intensi tersebut dengan berkooperasi dengan kompetitor Tiongkok, seperti Korea Selatan dan Jepang untuk menandingi inisiatif ambisius Tiongkok tersebut. Namun, penulis menemukan bahwa sejatinya India dan Tiongkok mengesampingkan rivalitas tersebut demi mewujudkan urgensi kepentingan nasional lain yang tidak kalah penting. Oleh karenanya, tulisan ini akan membahas nilai strategis Samudra Hindia, analisis teori, definisi dan trajektori BRI oleh Tiongkok, persepsi India terhadap BRI, respon counterbalance yang dilakukan India, dan ditutup dengan rekomendasi tindakan yang seharusnya dilakukan oleh kedua negara ini
\end{abstract}

Kata Kunci: BRI, Counterbalance, Hegemon, India, Tiongkok

The Indian Ocean and the surrounding region are strategic locations that attract many interested nations, including India and China. Both countries have competition based on the desire to be hegemon in order to spreading cultural, political, economic, and military influence beyond these waters. This competition has intensified since China initiated the Belt and Road Initiatives (BRI) that India has seen as a comprehensive strategy to increasingly validate Chinese hegemonic presence in the region which India claims as its responsibility. India also responds by cooperating with Chinese competitors, such as South Korea and Japan, to emulate China's ambitious initiative. However, after reviewing it, India and China should wisely put aside this rivalry in order to realize the urgency of other national interests that are equally as important. Therefore, this paper will discuss the strategic value of the Indian Ocean, the analysis of the theory, definition and trajectory of BRI by China, the real perception of India against BRI, counterbalance response by India, and recommendations for actions that should be taken by these two countries

Key Words: BRI, China, Counterbalance, Hegemon, India 


\section{Pendahuluan}

Samudra Hindia merupakan samudra terbesar ketiga di dunia yang melingkupi setidaknya seperlima dari total area laut di dunia. Samudra ini berperan integral dalam menyediakan rute perdagangan laut karena samudra ini menghubungkan kawasan Timur Tengah, Afrika, dan Asia Selatan, dan terletak di dalam benua Asia di bagian Timur, dan Eropa di sebelah Barat (Varma 2011 dalam Karim 2017). Lebih dari itu, negaranegara yang berada dalam Indian Ocean region (IOR) atau region Samudra Barat memiliki keuntungan berupa lokasi strategis. Dengan demikian, perdagangan dan aktivitas komersil kerap dilakukan melalui strategic choke points atau titik sempit strategis Samudra Hindia, yang berarti bahwa aktivitas melalui jalur laut mau tidak mau akan melewati titik ini. Meskipun demikian, sejatinya hal ini mengakibatkan persaingan dan obsesi masing-masing negara untuk mengamankan sumber dayanya, terutama energi, sebab hampir 40\% petroleum daratan diproduksi di Samudra Hindia (Karim 2017).

Fitur geopolitik dalam Samudra ini juga semakin memungkinkan untuk dikontrol melalui lima titik utama: (1) Tanjung Harapan yang terletak di ujung paling Selatan di Benua Afrika; (2) Selat Bab-el-Mandeb yang berada di ujung selatan Laut Merah; (3) Selat Hormuz di ujung Selatan Teluk Persia; (4) Selat Malaka yang terletak antara Malaysia dan Indonesia; dan (5) Selat Sundra antara Jawa dan Sumatra. Masingmasing titik ini juga memiliki signifikansi tersendiri, dengan titik pertama yang lokasinya memungkinkan untuk memantau rute pelayaran di sekitar Afrika, titik kedua dapat berfungsi untuk menjaga sisi ujung Selatan Terusan Suez, titik ketiga mengawasi arus minyak dari Teluk dan Jazirah Arab, dan terakhir titik keempat dan kelima dapat mengawasi lalu lintas kapal laut dari Indo-Pasifik ke dalam Samudra Hindia. Melalui beberapa titik sempit strategis tersebut, terutama di Selat Hormuz dan Malaka, sebanyak 32.2 juta barel minyak dan petroleum diangkut per hari, atau di kata lain, Samudra Hindia merupakan jalur dimana lebih dari 50\% perdagangan minyak dunia dilakukan (Karim 2017).

Dengan nilai-nilai strategis yang telah disebutkan di atas, tidak dapat dipungkiri bahwa Samudra Hindia memiliki daya tarik besar tidak hanya bagi negara-negara di sekitarnya, namun juga bagi negara adidaya layaknya Amerika Serikat dan Tiongkok yang merupakan kompetitor terbesar di area tersebut, dengan India sebagai aktor penyeimbang demi melindungi kepentingan nasionalnya. Alfred Thayer Mahan, seorang laksamana laut Amerika Serikat kenamaan, pernah menyatakan bahwa siapapun yang berhasil menguasai Samudra Hindia, maka dialah yang mendominasi seluruh Asia. Samudra ini merupakan kunci dari tujuh Samudra. Pada abad ke-21, hal ini pantas dipertimbangkan karena masa 
depan dari dunia pada akhirnya akan ditentukan dari samudranya (Karim 2017).

Berdasarkan segala kelebihan tersebut, dapat dipahami bahwa Tiongkok perlahan-lahan berupaya memanfaatkan Samudra Hindia, terutama di area Teluk Bengal, seiring dengan perkembangan militer dan ekonomi yang diimbangi dengan modernisasi yang pesat. Fokus utama Tiongkok berada di Selat Malaka dikarenakan mayoritas perdagangan ke arah Pasifik pasti melewati selat ini, dan Tiongkok sangat dependen terhadap suplai sumber daya energi yang datang dari Timur Tengah. Tidak hanya itu, terdapat asumsi yang beranggapan bahwa apabila suplai energi melalui Selat Malaka mengalami hambatan, bahkan untuk sehari saja, maka Tiongkok akan terkena dampak negatifnya. Oleh karena itu, keamanan maritim yang berpusat di Selat Malaka turut mendorong Tiongkok agar memanfaatkan Samudra Hindia. Intensi ini merupakan salah satu landasan formulasi kebijakan geopolitik strategis Tiongkok seperti String of Pearls dan Belt and Road Initiative (BRI), yang pada dasarnya menggambarkan tujuan utama Tiongkok di Samudra Hindia, yakni keuntungan ekonomi dan keamanan Sea Lines of Communication (SLOC), sebuah rute maritim utama antar pelabuhan yang digunakan tidak hanya untuk perdagangan, namun juga logistik dan angkatan laut. Oleh karenanya, dapat dipahami bahwa upaya Tiongkok untuk membangun pos-pos di wilayah tersebut bukan digunakan sebagai simbol kekuatan, namun digunakan sebagai akses (Karim 2017).

\section{Rumusan Permasalahan}

Strategi Tiongkok dalam mengakumulasikan upaya untuk menguasai Samudra Hindia tergambar secara eksplisit dalam program investasi infrastrukturnya yang masif. Program ini merupakan inisiatif Tiongkok pada tahun 2013 dan dikenal dengan BRI. Melalui BRI, Beijing menyediakan pinjaman dan menyediakan jaringan ekspansif, terdiri atas infrastruktur fisik dan komunikasi yang pada akhirnya akan menyatukan hingga hampir 60 negara di seluruh dunia. Inisiatif ini juga semakin meningkatkan kooperasi dua arah antara Tiongkok dengan negara di kawasan Asia Tenggara, Eropa, dan tentunya Asia Selatan. Tidak hanya itu, pandangan terhadap kesuksesan BRI ini berada dalam persepsi optimis karena melewati tiga rute utama yang masing-masing melewati Samudra Hindia yang menguntungkan. Lebih lanjut, melalui BRI, Tiongkok menjadi kandidat kuat untuk menjadi penguasa Samudra Hindia berkat adanya jaringan konektivitas yang kian mengkonsolidasikan Tiongkok secara progresif sebagai kekuatan regional di Samudra Hindia (Mishra 2008). 
Akan tetapi, diskusi mengenai BRI mendapat respon yang pesimistis, salah satu contohnya dari India. Dalam hal ini, India memandang BRI sebagai kebijakan luar negeri dan kebijakan keamanan hegemon Tiongkok yang ditutupi oleh program ekonomi. Oleh karena itu, BRI sebenarnya tidak hanya merefleksikan kepentingan komersil Tiongkok, namun juga memfasilitasi tujuan militer Tiongkok dalam mendominasi negara-negara tetangga atau mungkin sebagian dunia. Dengan latar belakang yang demikian, tulisan ini akan membahas mulai dari kajian teori yang dapat menjelaskan tindakan dan intensi Tiongkok melalui BRI, signifikansi dari BRI bagi Tiongkok dan beberapa negara yang menyetujui inisiatif ini, dan kemudian berlanjut pada pembahasan mengenai pandangan India terhadap Samudra Hindia dan BRI, respon India dan apa yang seharusnya dilakukan India guna menanggapi BRI.

\section{Kerangka Teori}

Keamanan merupakan asumsi utama dari teori klasik Hubungan Internasional, yakni realisme. Teori ini memandang dunia dengan perspektif realistis dan pragmatis. Teori ini berkutat dengan dua konsep utama dalam hubungan internasional, yakni keamanan dan kekuatan. Masing-masing negara pasti memosisikan keamanan nasional sebagai tujuan utama dan guna mencapai tujuan ini, kekuatan adalah katalis primer. Bagi pendukung realisme, situasi internasional adalah anarki dan tidak ada otoritas sentral yang mampu menjaga perdamaian dengan cara mengelola dan mengatur perilaku negara-bangsa. Argumen ini acap kontras dengan pemikiran liberalisme berikut organisasi internasionalnya. Absen dari otoritas pengatur ini menyebabkan situasi bernama security dilemma (Herz 1950 dalam Saxena 2017), dimana tiap negara dalam sistem politik internasional tidak akan bisa yakin dengan intensi dan kemauan dari negara lain, sehingga tiap negara tidak akan menurunkan batasan proteksi mereka terhadap diri sendiri (Holsti t.t., dalam Saxena 2017). Selain itu, realis juga berargumen bahwa negara akan memaksimalkan kekuatan nasionalnya demi keamanannya. J.J Mersheimer, seorang realis ofensif, menggarisbawahi dalam tulisannya berjudul the Tragedy of Great Power Politics (2001 dalam Saxena 2017) dengan menetapkan karakteristik hegemoni dari sebuah negara. Ia menguatkan argumen ini dengan elaborasi bahwa sistem internasional adalah anarki, dimana negara secara inheren memiliki kapabilitas militer ofensif yang memberikan alat yang diperlukan untuk menyakiti atau bahkan menghancurkan satu sama lain dengan motif dasarnya ialah survival (Mersheimer 2001 dalam Saxena 2017).

Menurut persepsi penulis, teori ini dapat menjelaskan intensi Tiongkok terutama dalam upayanya untuk mengabsahkan presensi hegemoninya di Samudra Hindia, didorong dengan adanya intensi String of Pearls 
dan BRI. Kedua strategi besar tersebut dipahami sebagai kemunculan dan peningkatan Tiongkok secara ofensif (Saxena 2017). Lebih dari itu, intensi India dalam upayanya untuk counterbalance peningkatan hegemon dari Tiongkok dapat dikaitkan dengan filosofi Morgenthau dalam Politics Among the Nations: The Struggle for Power and Peace (1948 dalam Saxena 2017), yang mendukung proposisi ini dengan landasan bahwa politik internasional, layaknya politik dalam konteks lain, adalah persaingan kekuatan.

Morgenthau (1948 dalam Saxena 2017) juga berargumen bahwa persaingan kekuatan terjadi di seluruh dunia, tak terkecuali negara berkapabilitas kecil atau besar. Setiap negara di dunia pasti memiliki rivalitas antar satu sama lain, sehingga memaksimalkan kekuatan nasional merupakan kebutuhan imperatif bagi negara untuk mengamankan kepentingannya. Burchill (2001 dalam Saxena 2017) juga menguraikan bahwa pencapaian kepentingan nasional merupakan hal lumrah, tidak dapat dihindari, dan adalah aktivitas yang diinginkan negara. Berdasarkan penjelasan teoretis tersebut, maka dapat dipahami bahwa Beijing sedang mengupayakan fondasi yang dapat membuktikan intensinya untuk mengkonsolidasi strategi maritimnya tidak hanya di masa kini, namun juga di masa depan. Hal ini jelas secara progresif diformalisasikan dengan terus mendorong strategi BRI-nya.

\section{BRI: Definisi dan Trajektori Tiongkok}

BRI merupakan strategi besar yang terdiri atas kombinasi dari dua inisiatif Tiongkok, yakni 21st Century Maritime Silk Road dan Silk Road Economic Belt. Masing-masing inisiatif diumumkan oleh Presiden Xi Jinping di tahun 2013. BRI juga dikenal sebagai One Belt One Road (OBOR). BRI merupakan insentif dengan trajektori dalam kurun waktu beberapa dekade yang dipandang dapat membentuk kembali hubungan komersial Tiongkok dengan dunia. Lima tujuan utama dari BRI adalah koordinasi kebijakan, konektivitas fasilitas, perdagangan tanpa rintangan, integrasi finansial, dan people-to-people. Inisiatif ini akan mengemban perusahaan multinasional terbaik dari Tiongkok, membangun infrastruktur dengan melintasi Asia, Afrika, Eropa, dan Timur Tengah, serta membentuk pasar baru bagi produk Tiongkok dan asing. BRI merupakan tahapan lanjutan dari upaya Tiongkok untuk mengglobal dan melakukan ekspansi atas pengaruh komersil dan politiknya (Baker McKenzie 2017).

Selain itu, mekanisme kooperatif bilateral maupun multilateral yang telah dimiliki Tiongkok juga dapat membantu akselerasi integrasi ekonomi antar negara seiring dengan rute BRI itu sendiri dan secara konstan mendukung pertumbuhan dalam perdagangan. BRI bersifat 
terbuka, tidak hanya dengan negara, namun juga organisasi. Mayoritas investasi dalam program inisiatif ini dikerahkan dalam infrastruktur, energi dan pertambangan, mulai dari pembangunan rel kereta api standar di Kenya hingga proyek hydropower di Kamboja dan deposit batu bara lignit di Pakistan. Terdapat dua perbedaan spesifik dari dua komponen BRI dan implikasinya bagi hubungan Tiongkok dengan firma asing. Pertama, the Belt merupakan koridor atau rute darat yang melewati Asia Tengah dan Eropa yang akan mengaitkan dua kekuatan ekonomi adidaya di dunia, yakni Tiongkok dan Eropa. Rute ini akan muncul sebagai jalur logistik dan akan membuat peluang baru bagi Asia Tengah dan Eropa Timur sebagai transhipment hub dan suplier komoditas, terutama dalam energi dan pertambangan. Sedangkan the Road, atau Maritime Road, adalah area yang penuh dengan konsumen dan peluang industri. Sama dengan the Belt, the Road ini mengaitkan antara Tiongkok dan Eropa, namun jalur yang dilewati adalah Asia Tenggara, Asia Selatan, Timur Tengah, dan Afrika Timur. Jalur ini disebut berpeluang besar karena region-region yang dilewati merupakan $63 \%$ dari populasi dunia dan menyumbang 44\% GDP dunia. Oleh karena itu, melewati Maritime Road inilah, MNCs dari banyak negara akan mendapat peluang signifikan dan berjangka panjang, bahkan tanpa perlu menghitung kesuksesan dari BRI sekalipun (Baker McKenzie 2017).

\section{Signifikansi BRI bagi Tiongkok dan Pendukungnya di Asia Selatan}

Inisiatif BRI digerakkan atas kepentingan domestik Beijing. Proyek infrastruktur yang terlibat di dalamnya akan membantu banyak industri Tiongkok yang mengalami kelebihan kapasitas, memicu pertumbuhan di region terpencil Tiongkok terutama wilayah Barat dan Barat Daya, serta dapat membawa teknologi Tiongkok ke arah serta posisi yang lebih dominan dalam kompetisi global di bidang rel kereta cepat, contohnya. Namun, selain mendorong pertumbuhan di negara penerima, inisiatif ini juga dapat menjadi diplomasi publik bagi Tiongkok dan secara langsung menunjukkan kemajuan negara ini sebagai hegemon regional (Kurlantzick 2018). BRI juga memiliki tujuan strategis bagi Tiongkok untuk membangun perusahaan berskala dunia dan dipandang sebagai ekstensi dari kebijakan Go Global Tiongkok di tahun 1990-an. Pemerintah Tiongkok pun mengharapkan BRI dapat mendukung restrukturisasi industrial. Hal ini disebabkan karena melalui BRI, perusahaan Tiongkok dapat belajar cara berkompetisi pada skala global, mengadopsi praktik internasional terbaik, mendapat teknologi terkemuka, dan menjadi pemain terbaik di pasar asing (Baker McKenzie 2017). 
Tanggapan negara-negara di region Samudra Hindia, dalam kasus ini Asia Selatan, memiliki spektrum polaritas: ada yang mendukung dan ada yang tidak mendukung. Namun, secara garis besar, Asia Selatan mendukung inisiatif BRI tersebut. Posisi ini dapat ditarik kembali dari sisi historis dengan beberapa kota kuno Asia Selatan, seperti Kathmandu, Patna, Kolkata, Delhi, Mathura, dan Taxilia yang membentuk bagian dari Jalur Sutra di era Dinasti Han pada tahun 130 SM. Para akademisi kenamaan dari Tiongkok dan Asia Selatan juga pernah melewati jalur ini. Oleh karenanya, ketika inisiatif BRI diutarakan oleh Presiden Xi Jinping, inisiatif ini dianggap membawa unsur-unsur peradaban kuno dari Jalur Sutra sebelumnya. Khusus pada wilayah Asia Selatan, BRI memiliki signifikansi tersendiri karena Tiongkok berbagi perbatasan seluas 5,00o-kilometer antar lima negara, yakni Nepal, India, Pakistan, Bangladesh, Bhutan, dan Afghanistan. Lebih dari itu, negara-negara tersebut juga pernah berbagi ikatan budaya, agama, dan komersial. Hal ini ditunjukkan dengan banyak negara Asia Selatan yang mendukung dan turut berpartisipasi dengan BRI guna mencapai kemakmuran bersama melalui investasi, konektivitas, dan perkembangan manufaktur. Dengan latar belakang yang demikian, dapat dipahami bahwa BRI akan memainkan peran instrumental guna mengarahkan kerjasama tersebut ke arah perdamaian, stabilitas, dan kemakmuran di region tersebut. Beberapa proyek yang menunjukan adanya kerja sama dan perkembangan zona perdagangan bebas antar negara antara lain seperti China-Pakistan Economic Corridor dan Qinghai-Tibet Railway yang mengaitkan Kerung, Kathmandu, dan Lumbini (The Rising Nepal t.t.)

\section{Persepsi India dalam Menanggapi Tiongkok dan BRI}

Pandangan India dalam melihat intensi Tiongkok sebagai hegemon Samudra Hindia didasarkan atas konsiderasi internal, yakni India memandang diri sendiri sebagai penyedia keamanan secara alami di Samudra Hindia. India memang merupakan aktor geopolitik terpenting di region ini, didukung dengan kapasitas militer dan ekonominya yang tidak dapat diremehkan. India juga memiliki 12 pelabuhan besar dan 200 pelabuhan kecil, semuanya tersebar di antara pesisir Timur dan Barat berikut pulau-pulaunya. Fakta ini menekankan pentingnya Samudra Hindia bagi maritim dan ambisi India (Karim 2017). Pada era modern ini, Samudra Hindia sering menjadi daya tarik unik bagi negara adidaya, seperti Amerika Serikat dan tak luput Tiongkok, yang merupakan kompetitor di region ini. India menjadi negara yang berupaya untuk menyeimbangkan posisi keduanya dengan melindungi kepentingan nasionalnya. Tidak dapat dipungkiri bahwa dengan semakin dependennya Hindia terhadap rute laut untuk impor dan ekspor kargo penting, kepentingan India meluas mulai dari Laut Arab 
dan Teluk Benggala hingga Samudra Hindia (Karim 2017). Samudra Hindia menjadi prioritas utama bagi kebijakan luar negeri India. Maka dari itu, etika Tiongkok mengumumkan inisiatifnya, respon India sejatinya dapat diprediksi. India merasa bahwa India yang seharusnya menjadi pembuat peraturan dan bukan pengikut.

Lebih lanjut, merujuk kembali pada salah satu argumen dalam teori realisme klasik, yakni dominasi, atau dalam hal ini dominasi laut, merupakan tindakan yang dibutuhkan untuk membentuk negara yang kuat. BRI dengan segala programnya merefleksikan hal tersebut. Oleh karena itu, Tiongkok menjadi kompetitor terbesar bagi India di region Samudra Hindia dan terus menjadi ancaman untuk dipertimbangkan. Hal ini dikarenakan India melihat Tiongkok sebagai negara yang berpotensi untuk menjadi tantangan bagi keamanan India. Selain itu, Tiongkok juga selalu berupaya untuk melakukan tindakan counter terhadap pengaruh India di Samudra Hindia. Dalam konteks ini, Brewster (2014 dalam Agra 2017) menyatakan bahwa kemampuan Tiongkok dalam memproyeksikan kekuatannya di Samudra Hindia akan terus mendorong Tiongkok untuk memanfaatkan Samudra Hindia semaksimal mungkin melalui choke points atau titik sempit, terutama di Selat Malaka. Tiongkok juga menerapkan kebijakan ekspansionis melalui peningkatan pengaruhnya di region Samudra Hindia dan membangun kerjasama dengan negara-negara litoral untuk melawan pengaruh India di Samudra ini (Agra, 2017). Oleh karenanya, muncul kekhawatiran dari India bahwa aset-aset infrastruktur maritim yang akan dibiayai Tiongkok melalui BRI di Samudra Hindia akan dipergunakan untuk tujuan militer dan strategis (Palit 2017).

Lebih dari itu, dari perspektif India, BRI merupakan proyek konektivitas regional yang dirancang semata-mata untuk mencapai kepentingan Tiongkok saja atau bertujuan untuk memenuhi visi Tiongkok secara eksklusif. Hal ini dibuktikan dengan perusahaan Tiongkok yang selalu dirujuk sebagai pemilik dari proyek infrastruktur BRI (Palit 2017). Akan tetapi, terdapat satu alasan vital lain yang membuat India merasa ragu dengan proyek BRI, yakni komitmen BRI dalam membuat rel, infrastruktur jalan, dan koridor perdagangan virtual yang mengaitkan Tiongkok Barat dengan pelabuhan Gwadar yang strategis di Pakistan. Proyek ini memungkinkan Tiongkok untuk mengangkut minyak dan gas dari Iran dan negara-negara Arab melalui pelabuhan Gwadar yang juga dikonstruksi oleh Tiongkok. Keberatan India disebabkan karena koridor perdagangan dan sambungan jalan rel tersebut melewati wilayah Kashmir yang diduduki Pakistan. Proyek BRI tersebut dipandang mengancam kedaulatan dan kepentingan utama India (Chibber 2017). Beijing juga dipandang tidak menghiraukan keberatan India dan tetap melanjutkan promosinya terhadap BRI. Pada Mei 14 sampai 15 tahun 2017, India memilih untuk tidak menghadiri Belt and Road Forum 
(BRF) for International Cooperation di Beijing. Gopal Baglay, juru bicara Menteri Luar Negeri India, mengafirmasikan keputusan tersebut dengan alasan bahwa India telah mencoba mendorong Tiongkok agar terlibat dalam dialog terkait inisiatif konektivitasnya dan India akan menunggu tanggapan positif terlebih dahulu. Tidak hanya itu, Boglay juga menyiratkan bahwa inisiatif konektivitas harus mengikuti prinsip tanggung jawab finansial guna menghindari utang berkelanjutan; standar proteksi ekologi dan kelingkungan dan pelestarian yang stabil; pengkajian biaya proyek yang transparan; dan transfer teknologi serta keahlian untuk menjamin kelangsungan dan pemeliharaan aset yang dibuat oleh komunitas lokal secara jangka panjang (Palit 2017). Berdasarkan alasan-alasan tersebut, India belum menunjukkan persetujuannya ataupun kooperasinya terhadap BRI

\section{Respon Counterbalance dari India: Inisiatif Baru dan Kerjasama Dengan Negara Kompetitor Tiongkok}

Pasca diumumkannya BRI, India genap memulai inisiatifnya di Samudra Hindia untuk counterbalance Tiongkok dan memastikan bahwa Tiongkok tidak akan bergerak terlalu jauh dalam mendominasi Samudra Hindia melalui String of Pearls dan BRI. Inisiatif maritim India di Samudra Hindia telah diproyeksikan sebagai Project Mausam, Spice Route, Cotton Route, the Blue Revolution, dan Security and Growth for All in the Region atau SAGAR. Inisiatif ini menempatkan India sebagai pusat sentral di lingkup Samudra Hindia. Akan tetapi, Tiongkok tetap berupaya keras agar dapat mencari cara untuk mengintegrasikan BRI dengan Mausam atau Spice Route India. India merumuskan Project Mausam untuk melakukan counter terhadap persepsi yang menganggap bahwa Tiongkok menjadi kekuatan adidaya di Samudra Hindia. Apabila dilihat dari permukaan, memang kedua proyek tersebut memiliki banyak persamaan dengan keduanya bertujuan untuk memperluas integrasi regional terutama dalam hal perdagangan dan komersil. Namun apabila dipantau lebih dalam, baik BRI maupun Project Mausam sejatinya mengenai memperluas pengaruh secara budaya, ekonomi, dan bahkan strategis (Chibber 2017).

Terlebih itu, India juga bekerja sama dengan kompetitor Tiongkok, seperti Korea Selatan dan Jepang dalam melancarkan responnya. Dari segi militer, India sukses menciptakan Special Strategic Partnership dengan Jepang dan Strategic Partnership dengan Korea Selatan dan Filipina. Lebih lanjut, India juga memiliki Strategic Partnership dalam konteks tradisional yang kuat dengan Vietnam dimana kooperasi pertahanan antar kedua negara dapat terlihat secara eksplisit. Tidak hanya itu, terdapat pula perkembangan kerjasama strategis antara India dengan Amerika Serikat dan Australia, yang dapat berakibat baik bagi stabilitas dan keamanan di Indo-Pasifik, khususnya benua Asia. 
Laksamana Angkatan Laut Jepang, Kazu Akimoto, mendukung kerjasama ini dengan menyatakan bahwa Samudra Hindia akan menjadi zona kepentingan strategis Jepang dan menekankan pada jalur perdagangan energi. Karena Tiongkok memiliki presensi militer kuat di first island chains, Jepang beserta aliansinya harus menetapkan posisi untuk melakukan stabilisasi di salah bagian samudra (Kamir 2017).

Melanjutkan lagi, Perdana Menteri Modi dari India juga memperbarui kebijakan di tahun 1990an bernama Look East menjadi kebijakan Act East di tahun 2014, sebagai wujud rivalitas terhadap Tiongkok dan juga mempromosikan perdagangan baru. Objektivitas dari kebijakan ini ialah untuk mengintensifikasi relasi ekonomi, politik, dan militer dengan Jepang dan negara anggota Association of Southeast Asian Nations (ASEAN). Lebih lanjut, India juga memiliki kebijakan Connect Central Asia dan seruntutan proyek jalan dan rel yang menjalar dari Asia Selatan dan Asia Tenggara, serta proyek perkembangan pelabuhan laut di Chabahar di Iran, dan kemungkinan di Paira, Bangladesh berikut Trincomalee di Sri Lanka. Selain itu, Jepang juga banyak terlibat dengan bidang perkembangan infrastruktur di Eurasia selama beberapa dekade ini, dengan membangun jalanan, jalur rel, sistem metro, dan pelabuhan di sekitar region melalui penggerak finansialnya seperti Asian Development Bank (ADB), Japan International Cooperation Agency (JICA), dan Japan Infrastructure Initiative (Shepard 2017). Berkaitan dengan kerja sama ini, maka dapat dilihat bahwa India dan Jepang memiliki relasi dan koordinasi yang saling menguatkan dan mutual dengan satu sama lain.

Relasi ini dibuktikan dengan kooperasi bilateral bernama Asia-Africa Growth Corridor (AAGC), dimana Jepang dan India berupaya untuk menciptakan model yang merupakan saingan dari inisiatif BRI milik Tiongkok. AAGC secara keseluruhan menargetkan Samudra Hindia dan runtutan negara pesisirnya, serta bertujuan untuk mengintegrasi ekonomi di Asia Selatan, Asia Tenggara, dan Asia Timur dengan Oseania dan Afrika. Gagasan utamanya adalah untuk menciptakan region IndoPasifik yang bebas dan terbuka melalui penemuan kembali rute laut kuno dan menciptakan koridor laut yang baru. Dalam prakteknya, AAGC dikonseptualisasikan sebagai segitiga ekonomi yang berbasis di laut, yang akan mengaitkan kota-kota dan pusat produksi melintasi region yang diprediksi akan bertumbuh pesat dan menjadi episentrum pertumbuhan ekonomi bersaing di dunia. Tidak dapat dipungkiri, Afrika dipandang sebagai frontier dalam perkembangan, sehingga AAGC berpotensi menjadi pedoman dasar interkonektivitas dan program perkembangan India dan Jepang lintas benua (Shepard 2017). 
Kerjasama India dan Jepang dalam mengembangkan jaringan ekonomi yang lebih komprehensif dengan melewati Asia dan Afrika, sesaat setelah BRI diresmikan, menunjukkan adanya dualitas geopolitik di Asia. Apabila dilihat secara seksama, ada dua tatanan yang berbeda: di satu sisi, Tiongkok dalam BRI memiliki proses top-down dan diatur oleh perusahaan dan institusi ekonomi pemerintah nasional, sedangkan di sisi lain terdapat blok yang dipimpin India dan Jepang, yakni AAGC, yang muncul dengan esensi demokrasi dan ekonomi liberal ala Barat (Shepard 2017). Memang apabila dibandingkan dengan Tiongkok, India memiliki sumber daya politik, ekonomi dan militer yang tidak dapat menandingi Tiongkok. Oleh karena itu, kooperasi ekonomi dan politiknya yang erat dengan Jepang dalam AAGC dapat menyediakan India instrumen baru untuk menjaga ambisinya di Samudra Hindia (Wagner dan Tripathi 2018).

Selain itu, dengan presensi Tiongkok yang kian meningkat, India juga mengiringi dengan menguatkan kooperasi militernya bersama Kepulauan Mauritius, Seychelles, Maldives, dan Komoros (Wagner dan Tripathi 2018). India juga menggiatkan program bernama International North-South Transport Corridor sebagai proyek trilateral, dengan Rusia, Iran dan India. Koridor tersebut dibangun di pelabuhan Chabahar, Iran. Pelabuhan ini dikembangkan di tahun 2016 dan selesai dibangun pada tahun 2017. Kota pelabuhan ini dibangun hanya sekitar $70 \mathrm{~km}$ dari pelabuhan Gwadar yang mana merupakan jalur the Belt dan the maritime Road milik BRI bertemu. Koridor ini dapat memberikan India akses terhadap Afghanistan dan meningkatkan perdagangan antar negara di masa mendatang, serta menjadi langkah inisiasi awal terhadap proyek infrastruktur yang sukses Asia Tengah, serta Rusia. Akan tetapi, sebagai akibat dari konfliknya dengan India, sejauh ini Pakistan menolak memberikan izin jaringan darat ke Asia Tengah dan telah memblokir segala upaya dari pemerintah Afghanistan untuk berdagang secara langsung dengan India (Wagner dan Tripathi 2018).

\section{Rekomendasi Kebijakan bagi India dan Tiongkok}

Meskipun BRI secara inheren berkaitan dengan geopolitik, India seharusnya tidak menolak atau menunggu kepastian Tiongkok terkait Pakistan terlebih dahulu, pun menutup mata atas dasar asumsi bahwa Tiongkok tidak lain adalah ancaman hegemon di Samudra Hindia. India seharusnya memanfaatkan BRI untuk mencari peluang yang berpotensi dapat mencapai kepentingan nasional India terutama perihal kompetitas ekonominya, yang ditawarkan oleh Tiongkok melalui BRI. India harus mengambil pendekatan pragmatis terhadap BRI secara lebih luas. Apabila India menghindari hubungan kerjasama, India dapat kehilangan peluang ekonomi signfikan, terutama karena proyek BRI dapat 
berkontribusi meningkatkan kapasitas infrastruktur maritim India. Tidak hanya itu, BRI juga menawarkan peluang bagi investasi asing Tiongkok untuk mengembangkan pelabuhan dan modernisasi logistik di India. Implikasi jangka panjang dari investasi jenis ini sangat positif dan berdampak pada kualitas infrastruktur domestik India, serta kemampuannya untuk melakukan bisnis dan berdagang di dunia. Lebih dari itu, posisi India yang kritis di segi strategi seharusnya dipandang menjadi berkah karena dapat menjadi pertimbangan saat bernegosiasi dan memastikan bahwa India dapat mendapat keuntungan dari BRI, serta menghindari efek kerugian yang mungkin terjadi. Dengan demikian, India seharusnya menunjukkan ketertarikan dan kemauan untuk bernegosiasi dan turut berpartisipasi dalam BRI (Palit 2017)

Pada sisi lain, Tiongkok seharusnya mengartikulasikan detail proyek BRI secara lebih spesifik, karena sejauh ini apa yang diketahui India masih berdasarkan ide dan visi yang dipromosikan Tiongkok. Visi dan ide tidak selamanya cukup menggerakkan sumber daya suatu negara untuk berpartisipasi dalam suatu inisiatif. Bukti dan aksi yang lebih mampu mendorong partisipasi. Oleh karena itu, Tiongkok harus terbuka dengan India terkait proyeknya, terutama proyek maritim, yang sedang direncanakan di Samudra Hindia dan perairan sekitarnya. Apabila hal ini sudah dilakukan, India dapat mengkaji proyek BRI dengan lebih objektif dan mencari titik peluang serta risiko. Sejauh ini, Tiongkok masih bersikap ambigu terhadap India. Oleh karena itu, dengan mengaitkan lagi pada teori security dilemma, India melakukan retaliasi dengan merumuskan Project Mausam. Sejatinya, respon jenis ini dapat mengubah region Samudra Hindia menjadi zona kontestasi geopolitik antara dua kekuatan besar Asia Selatan. Guna mengindari intensifikasi rivalitas geopolitik semacam ini, Tiongkok harus bertindak melampaui retorika diplomatik terkait keinginanya untuk tergabung dalam dialog akomodatif, dan menguatkan komunikasi pun koordinasi dengan India, dan betul-betul memberikan detail yang memungkinkan negosiasi konkrit untuk diwujudkan, menyingkirkan prospek atas resiko, dan mengindari ancaman terkait proyek BRI dengan negara partner dari India pula (Palit 2017).

\section{Kesimpulan}

Lokasi dari Samudra Hindia memiliki keuntungan strategis. Region yang berada di Samudra ini juga sangat kaya sumber daya alam. Namun, dengan prospek yang bagus, datang pula konflik dan kompetisi antar negara di region ini. Kompetisi yang dimaksud tidak hanya ekstraregional, namun juga intra-regional hingga aktor non-negara yang membawa ancaman non-tradisional layaknya terorisme dan pembajakan. Dalam konteks negara, negara yang paling kentara kompetisinya ialah antar Tiongkok dan India. Kompetisi antar kedua negara tersebut berkaitan erat dengan keinginan masing-masing dalam 
menyebarkan pengaruhnya di Samudra Hindia dan region sekitarnya. Didorong dengan Belt and Road Initiative (BRI), India melihat Tiongkok lebih sebagai ancaman dibanding peluang. BRI dipandang pemerintah India sebagai proyek atau inisiatif ekonomi yang ambisius, namun sebagai strategi komprehensif Tiongkok demi menyembunyikan kebijakan hegemoni dan keamanannya. Sebagai respon counterbalance presensi Tiongkok, India merumuskan alternatif untuk menantang negari panda ini, dengan mengembangkan format kooperasi baru bersama negara kompetitor Tiongkok, Korea Selatan dan Jepang.

Selain itu, penulis berpendapat bahwa memang secara historis India dan Tiongkok tidak terlalu memiliki relasi ekonomi kuat terlepas dari kekuatan nasional strategis dari kedua negara tersebut. Namun, BRI dapat menjadi insentif untuk berkooperasi dalam perdagangan dan investasi dibanding bersaing antar satu sama lain. Chibber (2017) memiliki data bahwa apabila India dan Tiongkok bekerjasama, kedua negara ini berakumulasi hampir 50\% dari ekonomi dunia. Tidak hanya itu, India merupakan kawasan yang terlalu krusial untuk diabaikan, sehingga apabila Tiongkok gagal menyadari pentingnya kolaborasi dari India, maka hal tersebut akan berdampak pada viabilitas BRI. Oleh karena itu, setidaknya kedua negara ini tidak berdiri di sisi spektrum yang berkontradiksi, melainkan di titik tengah, yakni berkooperasi dengan kompetitif. Jika posisi ini dikelola dengan baik oleh kedua pemerintahan, maka akan menciptakan keuntungan, namun bila tidak, maka akan menimbulkan konfrontasi terbuka yang akan sangat merugikan.

\section{Daftar Pustaka}

\section{Buku}

Baker McKenzie, 2017. Belt \& Road: Opportunity and Risk. The Prospects and Perils of Building China's New Silk Road.Hong Kong: Silk Road Associates.

Wagner, Christian, dan Siddharth Therapathi, 2018. India's Response to the Chinese Belt and Road Initiative. Germany: SWP Comments.

\section{Jurnal Ilmiah}

Chibber, Ajay, 2017. "China's Belt and Road Initiatives: Competitive Cooperation", Journal of Infrastructure, Policy \& Development, 1 (2).

Jacob, Jabin T., 2017. "China's Belt and Road Initiatives: Perspectives from India”, China \& World Economy, 25 (5). 
Karim, Mohd Aminul, 2017. "21st Century Maritime Power-Politics in the Indian Ocean Region with Special Reference to the Bay of Bengal", Pacific Focus: Inha Journal of International Studies, 32 (1).

\section{Artikel Daring}

Kurlantzick, Joshua, 2018. China's Risky Play for Global Power [Online].

https://washingtonmonthly.com/magazine/september-october2018/chinas-risky-play-for-global-power/ [diakses 21 September 2018].

Mishra, Vivek, 2018. China is Moving into the Indian Ocean [Online]. Dalam https://nationalinterest.org/feature/china-moving-theindian-ocean-25380 [diakses 20 September 2018].

Palit, Amitnendu, 2017. The Maritime Silk Road Initiatives: Why India is Worried, What China Can Do [Online] Dalam https://www.globalpolicyjournal.com/blog/31/o5/2017/maritimesilk-road-initiative-msri-why-india-worried-what-china-can-do [diakses 21 September 2018].

Shepard, Wade, 2017. India and Japan Join Forces to Counter China and Build Their Own New Silk Road [Online]. Dalam: https://www.forbes.com/sites/wadeshepard/2017/07/31/indiaand-japan-join-forces-to-counter-china-and-build-their-own-newsilk-road/\#f2e14514982c [diakses 21 September 2018].

The Rising Nepal, t.t. South Asia and BRI. [Online]. Dalam http://therisingnepal.org.np/news/20650 [diakses 21 September 2018].

\section{Disertasi}

Saxena, Antra, 2017. India's Policy Towards the Indian Ocean: A Study of Traditional and Non-Traditional Security Concerns. Phd Dissertation. Deemed University. 